\title{
New Pickering emulsions stabilized with chitosan/collagen peptides nanoparticles: Synthesis, characterization and tracking of the nanoparticles after skin application
}

\author{
Asma Sharkawy $^{\mathrm{a}, *}$, Maria Filomena Barreiro ${ }^{\mathrm{b}, *}$, Alírio E. Rodrigues ${ }^{\mathrm{a}, *}$ \\ ${ }^{a}$ LSRE-LCM, Department of Chemical Engineering, Faculty of Engineering, University of Porto, Rua Dr. Roberto Frias $s / n$, 4200-465, Porto, Portugal \\ ${ }^{\mathrm{b}}$ Centro de Investigação de Montanha (CIMO), Instituto Politécnico de Bragança, Campus de Santa Apolónia, 5300-253, Bragança, Portugal
}

\section{H I G H L I G H T S}

- Novel chitosan/collagen peptides stable Pickering emulsions were developed.

- The produced emulsions have shown shear-thinning and elastic gel-like behaviour

- The fate of the nanoparticles after emulsion skin application was investigated.

- Skin tracking of the nanoparticles showed their deposition in deep skin layers.

- Skin penetration is affected by the nanoparticle concentration and exposure time.

\section{A R T I C L E I N F O}

\section{Keywords:}

Pickering emulsions

Chitosan/collagen peptides

Skin applications

Rheology

Emulsion stability

Nanoparticles tracking
G R A P H I C A L A B S T R A C T

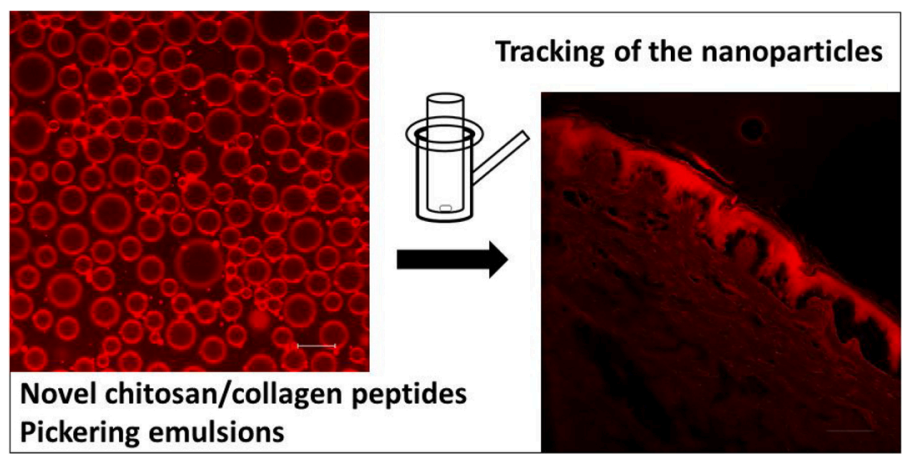$$
\text { Pickering emulsions }
$$

\begin{abstract}
A B S T R A C T
Pickering emulsions based on biopolymeric particles are gaining increasing research recognition in numerous applications due to their biocompatibility and eco-friendliness. In this work, chitosan/collagen peptides nanoparticles were applied to stabilize Pickering emulsions for potential cosmetic applications. The nanoparticles had a contact angle of $78.02^{\circ} \pm 2.04^{\circ}$, reflecting their hydrophilic nature. Their average size and zeta potential were $32.27 \mathrm{~nm}$ and $+59.7 \mathrm{mV}$, respectively. Confocal laser scanning microscopy (CLSM) showed that the nanoparticles become well-adsorbed at the oil-water interface. The emulsions displayed shear-thinning viscosity and gel-like texture. Their average droplet size ranged between $7.63 \mu \mathrm{m}$ and $15.72 \mu \mathrm{m}$. CLSM skin tracking of the nanoparticles, after ex vivo skin application of the Pickering emulsions, revealed the ability of the emulsion droplets to penetrate the stratum corneum and deposit in deeper skin layers. The penetration degree depends on the concentration of the nanoparticles in the emulsion and on the contact time with the skin. These results provide new insights into the fate of the nanoparticles used to stabilize Pickering emulsions following their skin application.
\end{abstract}

\footnotetext{
* Corresponding authors.

E-mail addresses: a.sharkawy@fe.up.pt (A. Sharkawy), barreiro@ipb.pt (M.F. Barreiro), arodrig@fe.up.pt (A.E. Rodrigues).
} 


\section{Introduction}

Sustainable cosmetics are gaining increasing interest in the industrial and academic sectors due to consumer demands towards safe and environmentally-friendly products with a "clean-label" [1]. Cosmetic emulsions, in the form of creams, lotions and gels are manufactured on a wide scale. These formulations contain surfactants that are used to disperse and emulsify the oil phase. Among the most commonly used surfactants in cosmetic emulsions are sodium lauryl sulfate, sodium dodecyl sulfate, sodium laureth sulfate, polyethylene glycol ethers, polysorbate 80, and sorbitan oleate (Span 80) [2]. Although these surfactants are very popular in cosmetic formulations, recent studies have shown that they have adverse effects on both the environment and human health as they have been reported to cause cytotoxicity and hemolysis [2,3]. Moreover, many surfactants that are used as emulsifiers or detergents can induce/evoke adverse skin reactions, such as inflammation and contact dermatitis [4].

Pickering emulsions are emulsions stabilized by solid particles that become adsorbed at the oil/water interface [5-7]. They are considered eco-friendly alternatives to the classical emulsion-based systems due to their emulsifier-free nature $[7,8]$. Pickering emulsions are finding increasing attention in the food and cosmetic applications [9-13]. Pickering emulsions based on biopolymeric particles, in particular, are increasingly becoming attractive vehicles in cosmetic and skin applications due to their non-toxic, biocompatible, and biodegradable properties [14-17].

Chitosan is a linear polysaccharide obtained from the deacetylation of chitin, which is a natural polymer that occurs in the exoskeleton of crustaceans. It is a copolymer that consists of D-glucosamine (deacetylated units) and N-acetyl-D-glucosamine (acetylated units) linked by $\beta-(1,4)$ glycosidic bonds [18]. Chitosan is classified as GRAS (Generally Recognized As Safe) [19]. Recently, chitosan-based particles have been used as successful Pickering emulsion stabilizers in various applications [14,17,20-23]. Chitosan has been used widely in cosmetic and skin formulations owing to its antibacterial, antioxidant, and skin regenerative properties [24,25], and also to enforce the circular economy principles for a sustainable cosmetic market [24]. It has also been used to enhance the stability of cosmetic formulations by acting as a stabilizer and a viscosifier (rheology modifier) [26]. Additionally, chitosan, when in the protonated form, has been reported to improve the cutaneous penetration of drugs and cosmeceuticals due to its ability to interact with the negative charges in the tight junctions of the stratum corneum (the outermost layer of the skin) [12,27-29]. Studies have also shown that chitosan changes the structure of keratin in the skin, decreases the cell membrane potential, and promotes cell membrane fluidity which leads to improving the cutaneous penetration [28].

Pickering emulsions stabilized with polysaccharide/protein complex particles have gained increasing research recognition as they demonstrate high stability and long shelf life [30]. Collagen peptides (collagen hydrolysates) are produced by the enzymatic, acidic or alkaline hydrolysis of collagen, the main structural protein present in the skin, bones and connective tissues [31]. Their low molecular weight has been reported to increase their bioavailability compared to their parent proteins. The utilization of collagen peptides in food supplements, cosmetic and pharmaceutical products is rapidly increasing [31,32]. The incorporation of collagen peptides in commercial cosmetic formulations has recently become exceptionally trendy due to their anti-aging properties. Collagenase enzyme is known to hydrolyze the collagen present in the skin, leading to dehydration and gradual loss of skin elasticity, and, subsequently, to the formation of wrinkles. Collagen peptides have been reported to have anti-collagenase activity, and thus help in preserving the indigenous skin collagen [33]. They have also been reported to possess anti-inflammatory and antioxidant properties [34].

Recent studies on Pickering emulsions developed for cosmetic and skin applications focused chiefly on tracking the fate of the active agent (the drug/cosmeceutical compound) that is incorporated/encapsulated in the dispersed phase $[12,17,35,36]$. However, to date, studies that explore the fate of the nanoparticles that stabilize Pickering emulsions intended for dermal and/or transdermal delivery are very scarce in the literature. Such studies are relevant to show how deep the nanoparticles of the Pickering emulsions can penetrate the skin. Additionally, these studies can open new dimensions for the use of the nanoparticles; as they can be tailored/designed to provide skin healing and therapeutic effects, alongside their primary function which is the stabilization of the emulsion. Unlike the case of Pickering emulsions, tracking of the nanoparticles and investigating their skin penetration and distribution has been tackled by several studies in which the particles acted individually as dermal and/or transdermal delivery vehicles [28,37-39]. In these studies, confocal laser scanning microscopy (CLSM) has proved to be a successful technique for the tracking of the particles.

The objective of this work is to develop novel stable Pickering emulsions stabilized with chitosan/collagen peptides nanoparticles for potential cosmetic applications. The work aims to investigate the microstructure, stability, and rheological properties of the produced Pickering formulations. Besides, since both polymers used in the production of the nanoparticles have skin benefits, the work aims to investigate the fate of the nanoparticles after skin application by tracking their skin distribution following the penetration of the emulsion droplets. To the best of our knowledge, this is the first study that explores the fate of chitosan-based particles after the topical application of Pickering emulsions.

\section{Materials and methods}

\subsection{Materials}

Chitosan (ChitoClear ${ }^{\circledR}$ ) with a molecular weight of $100-200 \mathrm{kDa}$, and a degree of deacetylation of $96 \%$ was a kind gift from Primex ehf, Iceland. Collagen peptides (the hydrolysed form of collagen type I), with a molecular weight of $5000 \mathrm{Da}$ and an isoelectric point of 5.2 , were obtained from HiMedia Laboratories, India. Olive oil (highly refined, low acidity), sodium tripolyphosphate (technical grade, $85 \%$ ), Nile Red and Nile Blue A (certified by the Biological Stain Commission) were purchased from Sigma Aldrich. Acetic acid ( $0.1 \mathrm{~N}$ standardized solution) was supplied by Alfa Aesar. The porcine skin samples were a kind gift from Grupo Primor, Portugal.

\subsection{Preparation of the chitosan/collagen peptides $(\mathrm{CH} / \mathrm{CP})$ nanoparticles}

The $\mathrm{CH} / \mathrm{CP}$ nanoparticles were produced by polyelectrolyte complexation followed by ionic gelation as described by Anandhakumar et al. [40], with some modifications. Dispersions with different concentrations of the nanoparticles were prepared; namely with $1 \%, 1.5 \%$, $2 \%$ and $2.5 \%(\mathrm{w} / \mathrm{v})$. Briefly, and taking the $1.5 \% \mathrm{w} / \mathrm{v}$ nanoparticles dispersion as an example, the preparation method comprised the next steps. Firstly, $0.75 \mathrm{~g}$ of chitosan was left overnight to dissolve in $50 \mathrm{ml}$ of $0.1 \mathrm{~N}$ acetic acid with magnetic stirring at $800 \mathrm{rpm}$. Thereafter, a solution of collagen peptides ( $\mathrm{pH}=6-6.2)$ was prepared by dissolving $0.75 \mathrm{~g}$ (the same amount as chitosan) in $15 \mathrm{ml}$ of deionized water and added to the chitosan solution $(\mathrm{pH}=4.2)$ under continuous stirring to prepare chitosan/collagen peptides $(\mathrm{CH} / \mathrm{CP})$ complex mixture $(\mathrm{pH}=4.7)$. Finally, $0.014 \mathrm{~g}$ of sodium tripolyphosphate (TPP) was dissolved in $35 \mathrm{ml}$ of deionized water and added dropwise over $30 \mathrm{~min}$ to the $\mathrm{CH} / \mathrm{CP}$ mixture under continuous stirring at $600 \mathrm{rpm}$. The mixture changed into an opalescent dispersion indicating the formation of the nanoparticles through the ionic gelation of the $\mathrm{CH} / \mathrm{CP}$ complex mixture by TPP [40]. The produced opalescent nanoparticle dispersion was kept under the same stirring rate for one hour. The $\mathrm{pH}$ of the produced $\mathrm{CH} / \mathrm{CP}$ nanoparticle dispersion was 5.08. All the steps were carried out at room temperature $\left(25^{\circ} \mathrm{C}\right)$. The amount of TPP was always kept at a content of $1.8 \%$ relative to the chitosan amount in all the produced $\mathrm{CH} / \mathrm{CP}$ nanoparticle dispersions (1\%, $1.5 \%, 2 \%$, and $2.5 \% \mathrm{w} / \mathrm{v})$. This low 
concentration of TPP was enough to form opalescent dispersions of nanoparticles. Higher concentrations of TPP relative to chitosan resulted in undesired precipitation.

\subsection{Preparation of the Pickering emulsions}

The emulsions stabilized with $\mathrm{CH} / \mathrm{CP}$ nanoparticles of different concentrations $(1 \%, 1.5 \%, 2 \%$, and $2.5 \% \mathrm{w} / \mathrm{v})$ were prepared by emulsifying $40 \mathrm{ml}$ of the nanoparticle dispersion with $60 \mathrm{ml}$ of olive oil using a high-speed homogenizer (Ultra-Turrax Digital T25, IKA, Germany) at 13,500 rpm for $6 \mathrm{~min}$. The oil was added slowly in a portionwise manner.

\subsection{Characterization of the produced $\mathrm{CH} / \mathrm{CP}$ nanoparticles}

\subsubsection{Morphology and size of the nanoparticles}

Transmission electron microscopy (TEM) was used to examine the morphology and size of the produced nanoparticles. The sample was prepared by mounting $10 \mu \mathrm{L}$ of the nanoparticle dispersion on Formvar/ carbon film-coated mesh nickel grids (Electron Microscopy Sciences, Hatfield, PA, USA). Afterward, negative staining was done by adding $10 \mu \mathrm{L}$ of $1 \%$ uranyl acetate onto the grids and left standing for $10 \mathrm{~s}$. Visualization was carried out with a JEOL JEM 1400 TEM at $120 \mathrm{kV}$ (Tokyo, Japan). Images were digitally recorded using a CCD digital camera Orious $1100 \mathrm{~W}$ (Tokyo, Japan). The average size of the nanoparticles was determined by using ImageJ software.

\subsubsection{Zeta potential of the nanoparticles}

The zeta potential of the produced $\mathrm{CH} / \mathrm{CP}$ nanoparticles $(1.5 \% \mathrm{w} / \mathrm{v})$, chitosan solution $(0.75 \mathrm{~g} / 50 \mathrm{ml}), \mathrm{CP}$ solution $(0.75 \mathrm{~g} / 15 \mathrm{ml})$, and $\mathrm{CH} /$ $\mathrm{CP}$ complex mixture (obtained by mixing chitosan and collagen peptides solutions) was determined using a Zetasizer Nano ZS ZEN3600 (Malvern Instruments Ltd., UK). The concentration of the samples was the same as the concentration of their solutions used in the production of the nanoparticle dispersion. The results were reported as the average of three runs for each sample.

\subsubsection{Wettability of the nanoparticles}

The wettability of the nanoparticles was determined using Dataphysics OCA15 Plus equipment (Dataphysics, Germany). All the measurements were conducted at room temperature $\left(25^{\circ} \mathrm{C}\right)$. For the wettability experiments, homogenous films of $\mathrm{CH} / \mathrm{CP}$ nanoparticle dispersion were prepared by depositing the dispersion $(1.5 \% \mathrm{w} / \mathrm{v})$ on glass slides, which were left to dry at room temperature. The contact angle of the nanoparticles was determined by injecting deionized water droplets ( $4 \mu \mathrm{l}$ each) onto the surface of the dried films. The shape of the droplet was photographed after $30 \mathrm{~s}$ for equilibrium [41,42] using a digital camera coupled to the equipment. The Young-Laplace equation was applied by the software to fit the profile data of the droplet. Measurements were taken as the average of at least 3 droplets on 2 different films of the same nanoparticle dispersion. The contact angle of chitosan and collagen peptides was also measured using the same method.

\subsubsection{Dynamic interfacial tension}

The interfacial tension was measured by the pendant drop method using the Dataphysics OCA15 Plus device (Dataphysics, Germany). Briefly, a drop of the $\mathrm{CH} / \mathrm{CP}$ nanoparticle dispersion $(1.5 \% \mathrm{w} / \mathrm{v})$ was formed by a submerged syringe inside a cuvette filled with olive oil. The interfacial tension was measured between $\mathrm{CH} / \mathrm{CP}$ nanoparticle dispersion and olive oil over $2400 \mathrm{~s}$ and was calculated by the pendant drop shape with the Young-Laplace equation using the equipment software. The measurements were also conducted between $\mathrm{CH} / \mathrm{CP}$ complex mixture and olive oil, as well as between chitosan solution and olive oil, and between collagen peptides solution and olive oil.

\subsection{Characterization of the Pickering emulsions}

\subsubsection{Droplet size}

The Pickering emulsion average droplet size was measured by a laser diffraction particle size analyzer (LS 230, Beckman Coulter, USA). The refractive indexes were set as 1.46 for olive oil and 1.33 for water. The measurements were done in triplicate for each sample.

\subsubsection{Creaming index}

The Creaming Index (CI\%) was determined for freshly prepared emulsions and after storage for two months to investigate the level of any potential phase separation. The emulsions were kept in sealed bottles to prevent water evaporation. CI\% was calculated using the following formula $[43,44]$ :

$C I \%=\frac{H s}{H t} \times 100$

where $\mathrm{H}_{\mathrm{s}}$ is the height of the serum layer and $\mathrm{H}_{t}$ is the total height of the emulsion.

\subsubsection{Microstructure}

The microstructure of the Pickering emulsions produced with different nanoparticle concentrations was analyzed using a Leica DM 2000 optical microscope equipped with a Leica Application Suite Interactive Measurement imaging software. The images were acquired at a magnification of $10 \times$.

Confocal laser scanning microscopy (CLSM) was used to examine the interfacial microstructure and confirm the type of the obtained Pickering emulsions. A fluorescent dye solution in isopropyl alcohol was prepared by mixing Nile Blue $(0.1 \% \mathrm{w} / \mathrm{v})$ and Nile Red $(0.1 \% \mathrm{w} / \mathrm{v})$ dyes. The Pickering emulsion samples were stained after their preparation by mixing $1 \mathrm{ml}$ of the fluorescent dye mixture with $35 \mathrm{ml}$ of the emulsion. Nile Blue was used to stain the $\mathrm{CH} / \mathrm{CP}$ nanoparticles, whereas Nile Red was used to stain the oil phase. The analysis was conducted using a Leica TCS SP5 CLSM (Leica Microsystems Inc., Germany). The applied excitation wavelengths were $633 \mathrm{~nm}$ and $488 \mathrm{~nm}$ for Nile Blue and Nile Red, respectively.

\subsubsection{Rheological properties}

The rheological properties of the Pickering emulsions were investigated using a Kinexus Pro Rheometer (Malvern, UK). For the steady flow assays, the apparent viscosity $(\eta)$ was measured versus shear rate (ranging from $0.1-100 \mathrm{~s}^{-1}$ ). These measurements were conducted using a cone plate with a diameter of $40 \mathrm{~mm}$, an angle of $4^{\circ}$, and a fixed gap of $0.15 \mathrm{~mm}$. The frequency sweep measurements were conducted at a constant strain amplitude of $1 \%$ (within the linear viscoelastic region) using a parallel plate of a diameter of $20 \mathrm{~mm}$ with a fixed gap of $1 \mathrm{~mm}$. The storage modulus $\left(\mathrm{G}^{\prime}\right)$ and loss modulus $\left(\mathrm{G}^{\prime \prime}\right)$ of the produced Pickering emulsions were measured over a frequency range of $0.01-10 \mathrm{~Hz}$. All the measurements were conducted at $25{ }^{\circ} \mathrm{C}$.

\subsection{Ex vivo skin application studies and tracking the fate of the nanoparticles}

\subsubsection{Skin preparation and Pickering emulsions application}

Dorsal porcine skin samples were obtained from pigs slaughtered at a local slaughterhouse with permission from the General Directorate of Food and Veterinary Medicine (DGAV, Portugal). The skin samples were shaved by an electric shaver (LS7140 Grundig, Grundig Intermedia $\mathrm{GmbH}$, Germany). The subcutaneous fat layer was carefully removed with a surgical scalpel according to the OECD guidelines [45]. The skin samples were then rinsed with water, wrapped in parafilm and aluminum foil, and stored at $-20^{\circ} \mathrm{C}$ until used.

The produced Pickering emulsions stabilized with $1 \%$ and $2 \% \mathrm{w} / \mathrm{v}$ $\mathrm{CH} / \mathrm{CP}$ nanoparticles were stained by Nile Blue $(0.1 \% \mathrm{w} / \mathrm{v})$ by mixing 
$1 \mathrm{ml}$ of the dye solution with $35 \mathrm{ml}$ of the emulsions. The stained emulsion samples were then applied to the skin using Franz diffusion cells (PermeGear, USA). Briefly, the skin samples were left to thaw at room temperature for $1 \mathrm{~h}$ before the experiments. They were then mounted between the donor and the receptor compartments of the Franz diffusion cells, with the stratum corneum side facing the donor compartment. Afterward, a sample of $300 \mu \mathrm{l}$ of Pickering emulsion formulation was added to the donor compartment and spread uniformly on the skin. The receptor fluid consisted of a 1:1 mixture of ethanol and PBS ( $\mathrm{pH} 7$ ), which was kept under magnetic stirring. The addition of ethanol to the receptor fluid is in accordance with the OECD guidelines for the ex vivo skin permeation experiments [45], and with previously reported methodologies [28]. The experiment was conducted under occlusive conditions to prevent water evaporation from the formulations, as previously reported $[46,47]$. The temperature was kept at $32{ }^{\circ} \mathrm{C}$ using a thermostatic water bath. The contact time of the formulations with the skin (the duration of the experiment) was set as $6 \mathrm{~h}$, as well as $24 \mathrm{~h}$ for each formulation. At the end of the experiment, the skin samples were collected, rinsed with water thoroughly (to remove any residual formulation remaining on the surface), placed in a tissue freezing me$\operatorname{dium}\left(\right.$ Killik ${ }^{\circledR}$, Bio-Optica), and kept in an ultra-low temperature freezer $\left(-78^{\circ} \mathrm{C}\right)$ until cryo-sectioning.

\subsubsection{Skin distribution and tracking of the $C H / C P$ nanoparticles}

Confocal laser scanning microscopy (CLSM) was used to track the nanoparticles and explore their distribution in the skin after the topical application of the emulsion formulations. For this purpose, the skin samples treated with Pickering emulsions stabilized with $1 \%$ and $2 \% \mathrm{w} /$ v CH/CP nanoparticles (labeled with Nile Blue) were cryo-sectioned using a cryostat (Cryostat Leica CM 3050S) to sections with a thickness of $20 \mu \mathrm{m}$. The skin sections were visualized with CLSM at an excitation wavelength of $633 \mathrm{~nm}$.

\subsection{Statistical analysis}

The results were presented as the mean \pm standard deviation using Microsoft Excel 365. The statistical comparisons were performed using one-way analysis of variance (ANOVA) and the independent sample $t$ test (with the level of significance at $p$ values $<0.05$ ) [48].

\section{Results and discussion}

\subsection{Production and characterization of $\mathrm{CH} / \mathrm{CP}$ nanoparticles}

\subsubsection{Morphology, size and zeta potential of the nanoparticles}

$\mathrm{CH} / \mathrm{CP}$ nanoparticles were prepared by complexation between the positively charged chitosan polymer chains and the negatively charged collagen peptides, followed by ionic gelation between the positively charged $\mathrm{CH} / \mathrm{CP}$ complex mixture and the polyanions of sodium tripolyphosphate (TPP) [40]. TEM images (Fig. 1) show that the produced $\mathrm{CH} / \mathrm{CP}$ nanoparticles have an average size of $32.27 \mathrm{~nm} \pm 10.14 \mathrm{~nm}$, with a minimum measured size of $14.40 \mathrm{~nm}$ and a maximum one of $59.39 \mathrm{~nm}$. The images also show that the nanoparticles are irregularly spherical and oval.

The produced $\mathrm{CH} / \mathrm{CP}$ nanoparticles are positively charged and have an average zeta potential of $+59.7 \pm 2.66 \mathrm{mV}$, as shown in Table 1 . It was also observed that the collagen peptide solution has a negative zeta potential $(-16.1 \pm 0.361 \mathrm{mV})$, which allowed the polyelectrolyte complexation with the positively charged chitosan. The complexation between the two polymers occurs mainly through hydrogen bonding between chitosan and collagen peptides [40], as well as via the electrostatic interaction between the oppositely charged chitosan and collagen peptides, which was evident in the observed decrease in the zeta potential of chitosan solution from $+79.4 \pm 3.71 \mathrm{mV}$ to $+62.3 \pm 2.1 \mathrm{mV}$ during the $\mathrm{CH} / \mathrm{CP}$ complex mixture formation. The $\mathrm{CH} / \mathrm{CP}$ nanoparticles were then obtained by the ionic gelation between the polyanions TPP and $\mathrm{CH} / \mathrm{CP}$ complex mixture which decreased the zeta potential slightly from $+62.3 \pm 2.1 \mathrm{mV}$ to $+59.7 \pm 2.66 \mathrm{mV}$. Although the amount of the used TPP is small, which is reflected in this slight decrease in the zeta potential value, the step of the ionic gelation by TPP was important for the production of the nanoparticles. The addition of TPP resulted in the transition of the transparent $\mathrm{CH} / \mathrm{CP}$ complex mixture into an opalescent nanoparticle dispersion.

\subsubsection{Wettability of the nanoparticles}

Solid particles that are used as emulsion stabilizers should have adequate wettability to allow them to be available at the oil/water interface. The wettability of the particles is calculated by the contact angle value which determines their hydrophilic or lipophilic nature, and hence the type of the Pickering emulsion they can stabilize. Particles that have a contact angle less than $90^{\circ}$ are hydrophilic and produce $\mathrm{o} / \mathrm{w}$ Pickering emulsions, while particles with a contact angle higher than $90^{\circ}$ are hydrophobic and form w/o emulsions [49-51]. Particles with a contact angle of $90^{\circ}$ are wetted equally by the oil and water phases, and theoretically, result in the formation of emulsions with optimized stability. However, in practical terms, it has been reported that emulsion stability is enhanced when a slightly greater part of the particle is placed in the continuous phase, i.e., when the particle has a slightly higher

Table 1

Zeta potential values of chitosan and collagen peptides solutions, complex mixture, and nanoparticles.

\begin{tabular}{ll}
\hline Sample & Zeta potential $(\mathrm{mV})$ \\
\hline Chitosan (CH) solution & $+79.4 \pm 3.71$ \\
Collagen peptides (CP) solution & $-16.1 \pm 0.361$ \\
CH/CP complex mixture & $+62.3 \pm 2.1$ \\
CH/CP nanoparticles & $+59.7 \pm 2.66$ \\
\hline
\end{tabular}

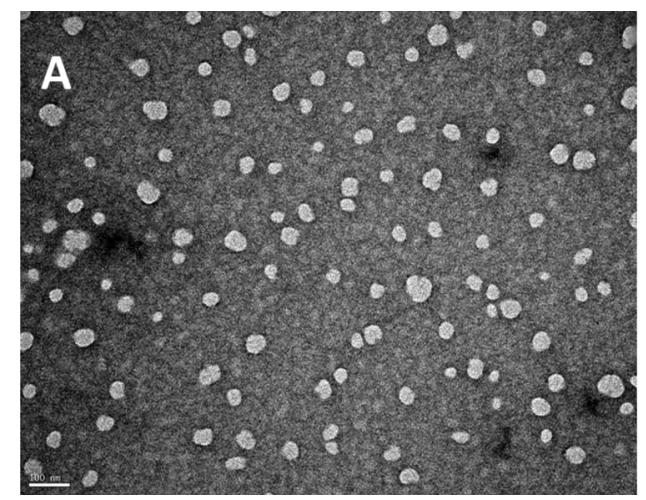

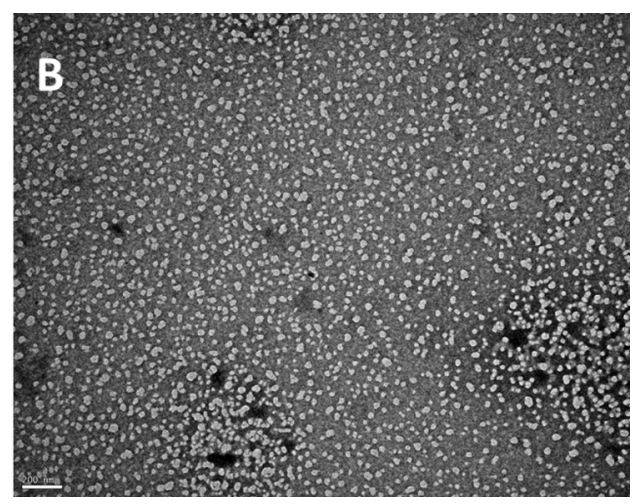

Fig. 1. TEM images of chitosan/collagen peptides nanoparticles at a magnification of (A) $100000 \mathrm{X}$, scale bar $=100 \mathrm{~nm}$, and $(\mathrm{B}) 50000 \mathrm{X}$, scale bar $=200 \mathrm{~nm}$. 
affinity to the external phase [50]. In this work, it was observed that the contact angle of the $\mathrm{CH} / \mathrm{CP}$ nanoparticles was $78.02 \pm 2.04^{\circ}$ (Fig. 2), which reflects their hydrophilic nature. It was also observed that the contact angle of the produced $\mathrm{CH} / \mathrm{CP}$ nanoparticles was higher than that of chitosan $\left(63.89 \pm 1.08^{\circ}\right)$ and also higher than that of collagen peptides $\left(33.67 \pm 2.92^{\circ}\right)$. These values suggest that the interaction between collagen peptides and chitosan to form the nanoparticles decreased the hydrophilicity of both polymers, which would enhance their ability to be adsorbed at the oil/water interface and hence produce more stable emulsions. It has been reported that during the formation of complex chitosan/collagen peptides nanoparticles, the long chitosan chains fold around the collagen peptides and form a new phase complex having properties different from the ones of the individual components [40]. The process was stated to occur mainly via hydrogen bonding. In this work, the decreased hydrophilicity of the produced $\mathrm{CH} / \mathrm{CP}$ nanoparticles could be attributed to the preferential orientation of the hydrophobic units of chitosan (N-acetyl-D-glucosamine units) towards the nanoparticle surface since the hydrophilic groups become internally involved in the hydrogen bonding with the collagen peptides.

\subsubsection{Interfacial tension}

The dynamic interfacial tension measures the degree of the assembly/adsorption of the nanoparticles at the oil/water interface [52-54]. Fig. 3 shows that the pure collagen peptides (CP) solution has lower interfacial tension than the chitosan $(\mathrm{CH})$ solution, indicating that the $\mathrm{CP}$ solution is more interfacially active than the $\mathrm{CH}$ solution. It can also be observed that the $\mathrm{CH} / \mathrm{CP}$ nanoparticles and the $\mathrm{CH} / \mathrm{CP}$ complex mixture have lower interfacial tension than the chitosan solution, reflecting that the interaction between collagen peptides and chitosan enhanced the interfacial properties relative to chitosan. This observation suggests that the interaction between the two polymers exposed more hydrophobic domains/moieties facilitating the adsorption at the oil/water interface (as discussed previously in Section 3.1.2). It has been reported that the exposure (uncovering) of the non-polar N-acetyl-D-glucosamine units of chitosan confers some hydrophobic features to the chitosan particles and improves their surface activity [55]. Fig. 3 also shows that the $\mathrm{CH} / \mathrm{CP}$ nanoparticles exhibited slightly lower interfacial tension than that of the $\mathrm{CH} / \mathrm{CP}$ complex mixture throughout the experiment indicating that $\mathrm{CH} / \mathrm{CP}$ nanoparticles have higher adsorption ability at the oil/water interface than the $\mathrm{CH} / \mathrm{CP}$ complex mixture.

\subsection{Production and characterization of the Pickering emulsions}

\subsubsection{Visual appearance and average droplet size of Pickering emulsions}

The formulation of cosmetic products containing sustainable and biodegradable materials can be extremely challenging due to instability constraints [1]. The stability of emulsions is determined by the creaming index (CI\%) and the size variation of the emulsion droplets during storage [56]. Pickering emulsions are generally known to have higher stability than classical emulsions. Digital photographs of freshly

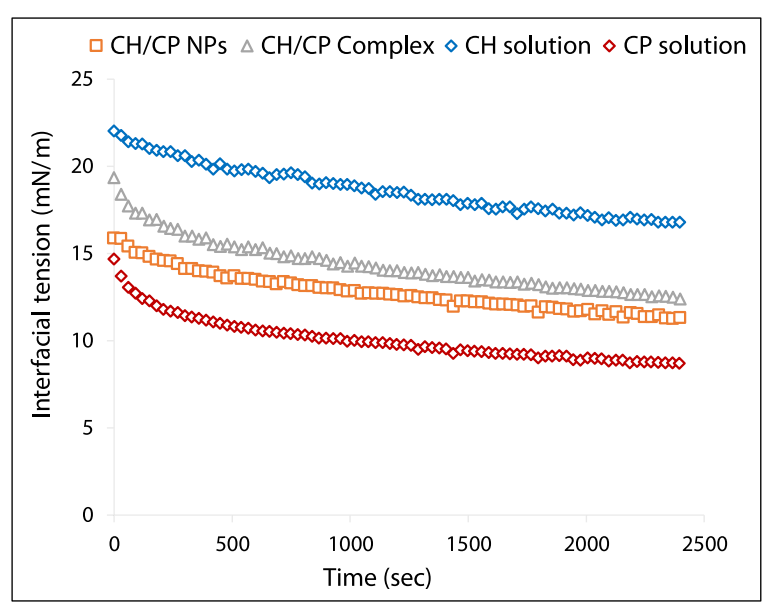

Fig. 3. Dynamic interfacial tension at the olive oil/water interface with the adsorption of chitosan (CH) solution, chitosan/collagen peptides complex mixture ( $\mathrm{CH} / \mathrm{CP}$ complex), chitosan/collagen peptides nanoparticles $(\mathrm{CH} / \mathrm{CP}$ NPs), and collagen peptides (CP) solution.

prepared and stored Pickering emulsions stabilized by $\mathrm{CH} / \mathrm{CP}$ nanoparticles with concentrations of $1 \%, 1.5 \%, 2 \%$, and $2.5 \% \mathrm{w} / \mathrm{v}$ are shown in Fig. 4A. No phase separation was observed in the freshly prepared formulations $(\mathrm{CI} \%=0)$, which was maintained after two months of storage except for the formulation stabilized with nanoparticle concentration of $1 \% \mathrm{w} / \mathrm{v}$. Unchanged $\mathrm{CI} \%$ after storage indicates excellent Pickering emulsion stability [41]. The formulation stabilized with $1 \% \mathrm{w} / \mathrm{v} \mathrm{CH} / \mathrm{CP}$ nanoparticles showed a CI\% of $9.09 \%$ after a storage period of two months, implying low water retention ability due to the weak structural network of the formed Pickering emulsion. However, $\mathrm{CI} \%$ values were unchanged $(=0 \%)$ as the nanoparticle concentration increased due to the presence of a stronger and more compact network structure, leading to better water retention, and hence to higher stability [57]. It is noteworthy that the used chitosan to collagen peptides mass ratio of 1:1 was used since it resulted, based on preliminary studies, in the formation of both stable $\mathrm{CH} / \mathrm{CP}$ nanoparticles and stable Pickering emulsions.

Fig. 4B shows the average droplet size of the produced Pickering emulsions measured directly after preparation, and after a storage period of 2 months. The freshly prepared emulsions were characterized by an average droplet diameter ranging between $7.63 \pm 0.20 \mu \mathrm{m}$ and $15.72 \pm 0.19 \mu \mathrm{m}$, which increased slightly to $10.19 \pm 0.46 \mu \mathrm{m}$ and $17.19 \pm 0.98 \mu \mathrm{m}$ after storage. It can be noticed that the size of the emulsion droplets is much larger than the size of the nanoparticles (as shown previously in the TEM images in Fig. 1), which is in agreement with the prerequisite that the size of the particles should be at least one order of magnitude smaller than the oil droplets for the Pickering emulsions to be formed [56]. Additionally, Fig. 4B shows that the
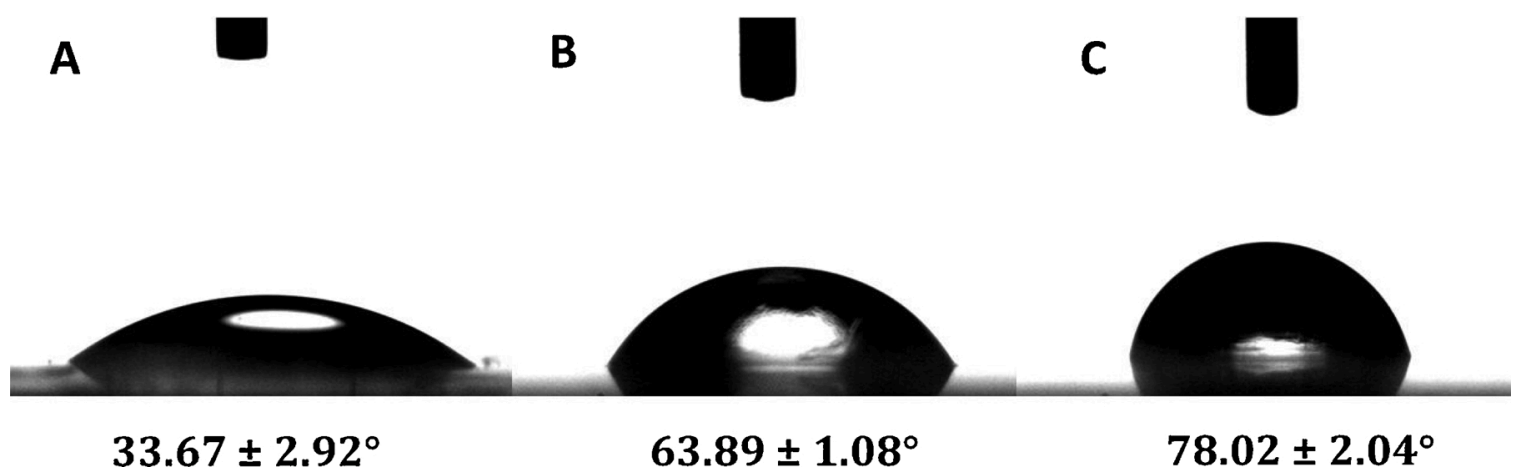

Fig. 2. Contact angle in the air environment of A) Collagen peptides, B) Chitosan, and C) Chitosan/collagen peptides nanoparticles. 


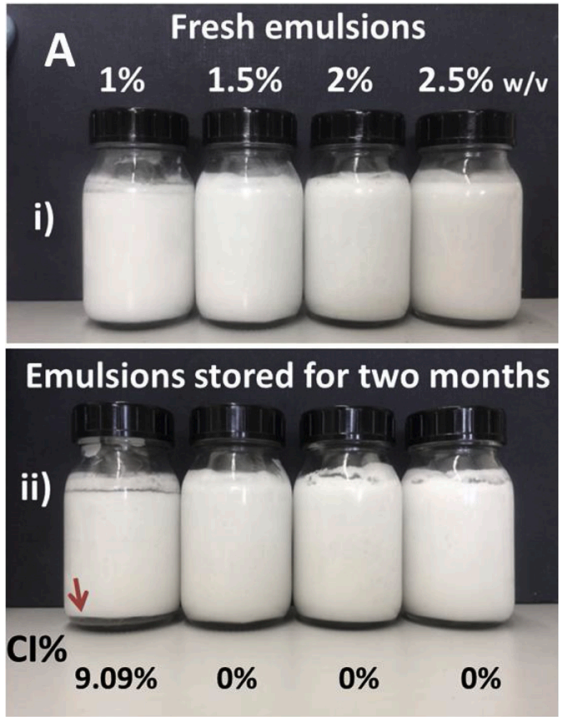

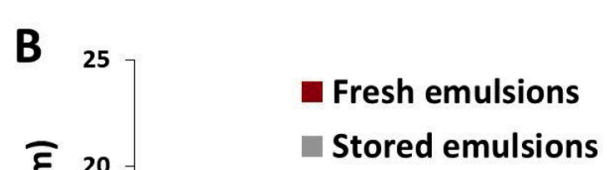

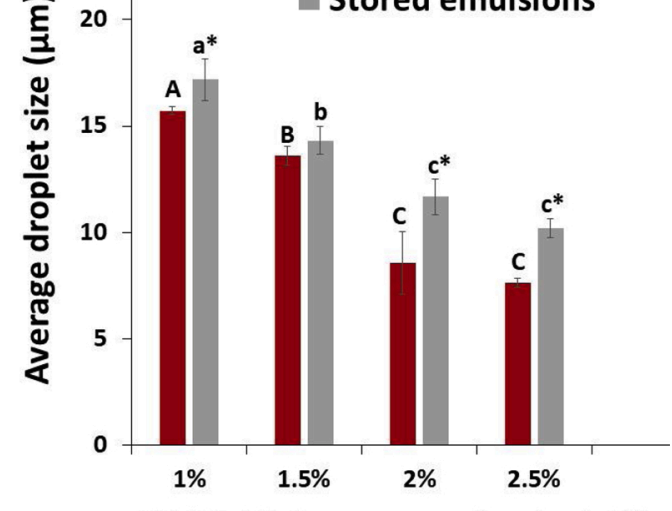

$\mathrm{CH} / \mathrm{CP}$ NPS concentration ( $\mathrm{w} / \mathrm{v} \%)$
Fig. 4. (A) Photographs of Pickering emulsions stabilized with chitosan/collagen peptides nanoparticles prepared with concentrations of $1 \%, 1.5 \%, 2 \%$, and $2.5 \%(w / v)$ : (i) Freshly prepared emulsions and (ii) Emulsions stored for two months at room temperature with the corresponding creaming index value (CI\%). The arrow (if present) shows phase separation. (B) The average emulsion droplet size of the produced Pickering emulsions. Different uppercase letters (A-C) indicate significant differences in the average droplet size between the fresh emulsions prepared with different $\mathrm{CH} / \mathrm{CP}$ NPs concentrations $(p<0.05)$, different lowercase letters (a-c) indicate significant differences in the stored emulsions with different $\mathrm{CH} / \mathrm{CP}$ NPs concentrations $(p<0.05)$, and * (if present) indicates significant differences between the fresh and stored emulsions with the same $\mathrm{CH} /$ CP NPs concentration $(p<0.05)$. droplet size of the produced Pickering emulsions significantly decreased as the nanoparticle concentration increased. At a fixed oil fraction, the dispersed phase is initially broken into small droplets by homogenization to the same extent. These droplets tend to coalesce to reduce the interfacial area. At higher particle concentrations, more particles are available to adsorb at the oil/water interface preventing the droplets from coalescence and resulting in the decrease of the droplet size [41]. Fig. 4B also shows a significant difference in the average droplet size of some formulations after storage $(\mathrm{p}<0.05)$. However, this variation is noticeably low which suggests that the produced Pickering emulsions are less susceptible to aggregation or coalescence [58], and implies good storage stability as evidenced by the absence of phase separation after storage.

\subsubsection{Morphology and interfacial structure of Pickering emulsions}

Optical microscopy images (Fig. 5) show that the droplets of the produced Pickering emulsions were all intact and spherical. It can be observed that the droplet size decreases as the $\mathrm{CH} / \mathrm{CP}$ nanoparticle concentration increases, which is in agreement with the results of the average droplet size shown in Section 3.2.1. Moreover, the optical microscopy images show that the microstructure of the formulations becomes more compact as the nanoparticle concentration increases. This could be explained by the fact that by the increase of the nanoparticle concentration, more nanoparticles were available to become adsorbed at the oil/water interface and form a dense network structure resulting in the decrease of the emulsion droplet size [57,59]. Additionally, this compact/dense network structure hinders the collision of the droplets, preventing their coalescence and Ostwald ripening, and hence enhances
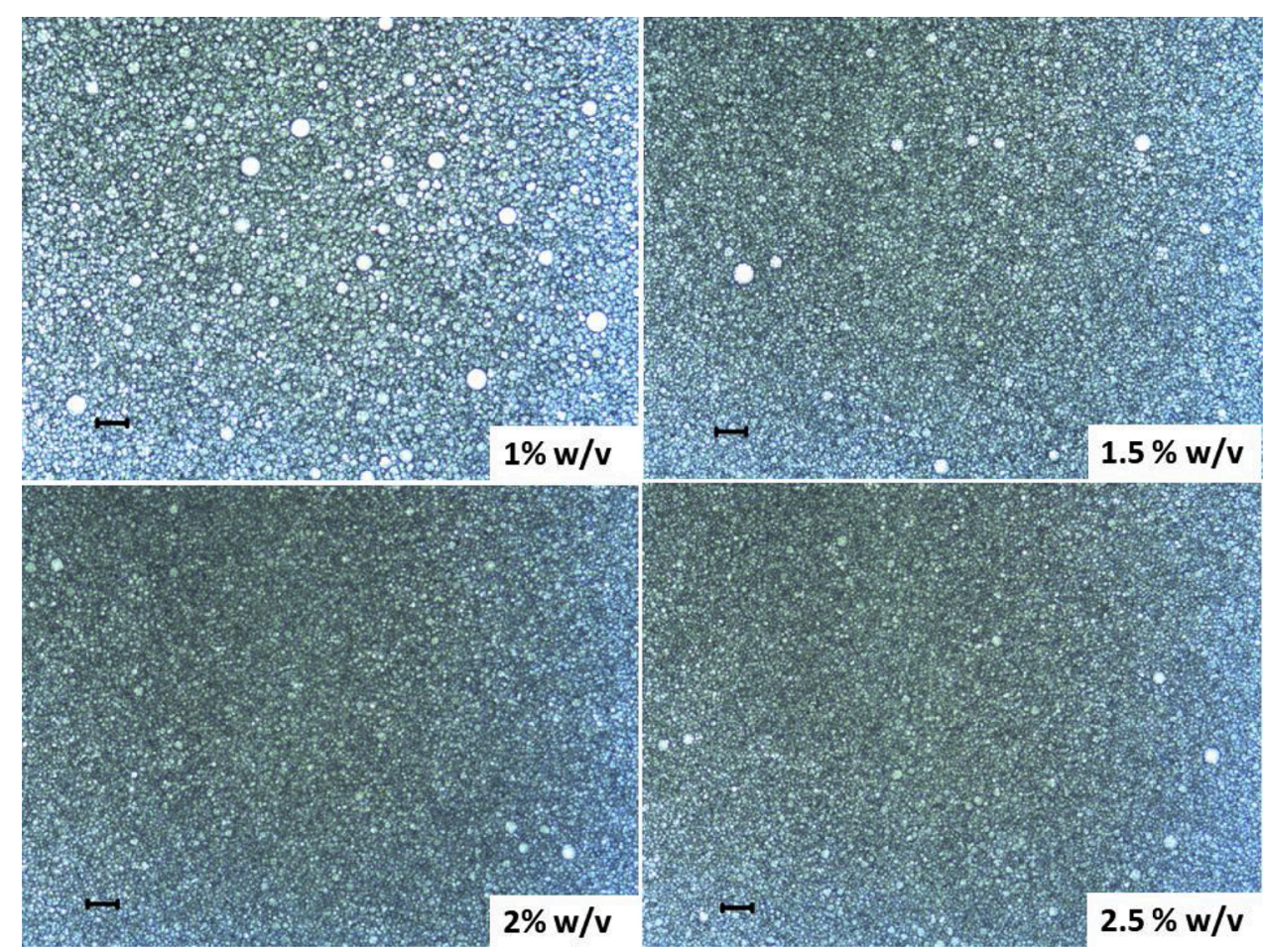

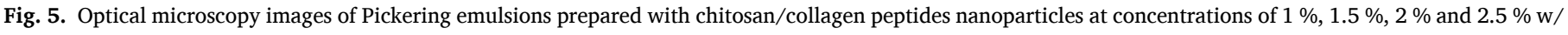
v. Scale bar $=20 \mu \mathrm{m}$. 
the emulsion stability [57].

The interfacial structure of Pickering emulsions stabilized with $\mathrm{CH} /$ $\mathrm{CP}$ nanoparticles $(1.5 \% \mathrm{w} / \mathrm{v})$ was investigated by the CLSM. The images (Fig. 6) show that the nanoparticles form a dense layer (appears in red) around the oil droplets (appear in green), indicating efficient nanoparticle adsorption at the oil/water interface. The CLSM images also confirm that produced Pickering emulsions stabilized with $\mathrm{CH} / \mathrm{CP}$ nanoparticles are $\mathrm{o} / \mathrm{w}$ emulsion type.

\subsubsection{Rheological properties}

The rheology of topical Pickering formulations is an important quality parameter [60]. In this study, the apparent viscosity of the produced Pickering emulsions decreased with the increase of shear rate from $0.1-100 \mathrm{~s}^{-1}$ as shown in Fig. 7A, indicating that the emulsions demonstrate a shear-thinning and non-Newtonian fluid behavior [61]. The shear-thinning behavior is a desirable feature for topical formulations as it facilitates the application of the product on the skin [62], and leaves a smooth sensorial feeling [2]. It can also be observed that the apparent viscosity of the produced emulsions increased with the increase of $\mathrm{CH} / \mathrm{CP}$ nanoparticle concentration from $1 \% \mathrm{w} / \mathrm{v}$ to $2 \% \mathrm{w} / \mathrm{v}$. This increase in the apparent viscosity subsequently leads to higher stability due to the formation of a network structure that restricts/limits the emulsion droplet movement and hence prevents aggregation, coalescence, and creaming [57].

The strength of the network structure can be determined from the storage modulus $\left(\mathrm{G}^{\prime}\right)$ which indicates the elastic properties of the emulsion, and the loss modulus $\left(G^{\prime \prime}\right)$ that indicates the viscous properties of the emulsion [63]. The results of the dynamic oscillatory measurements of the Pickering emulsions with the frequency ranging from $0.01-10 \mathrm{~Hz}$ are shown in Fig. 7B. It can be noted that the values of $\mathrm{G}^{\prime}$ and $\mathrm{G}^{\prime \prime}$ increased by increasing the $\mathrm{CH} / \mathrm{CP}$ nanoparticle concentration, which can be attributed to a higher particle adsorption rate leading to the formation of a stronger network structure [57]. Additionally, it can be observed that the values of $G^{\prime}$ were higher than $G^{\prime \prime}$ for both formulations, implying the formation of an elastic gel-like network in the formed Pickering emulsions. Higher values of $\mathrm{G}^{\prime}$ than $\mathrm{G}^{\prime \prime}$ also indicate that the reversible deformation of the emulsion droplets is greater than the irreversible deformation because of the dominating elastic gel-like behavior [10].

\subsection{Skin distribution and tracking of the $\mathrm{CH} / \mathrm{CP}$ nanoparticles}

The skin distribution of the nanoparticles stabilizing the Pickering emulsion formulations was investigated after 6 and $24 \mathrm{~h}$ of skin application. Fig. 8 shows the CLSM images of porcine skin sections treated with Pickering formulations stabilized with $1 \%$ and $2 \% \mathrm{w} / \mathrm{v} \mathrm{CH} / \mathrm{CP}$ nanoparticles. Higher fluorescence intensity was observed in samples
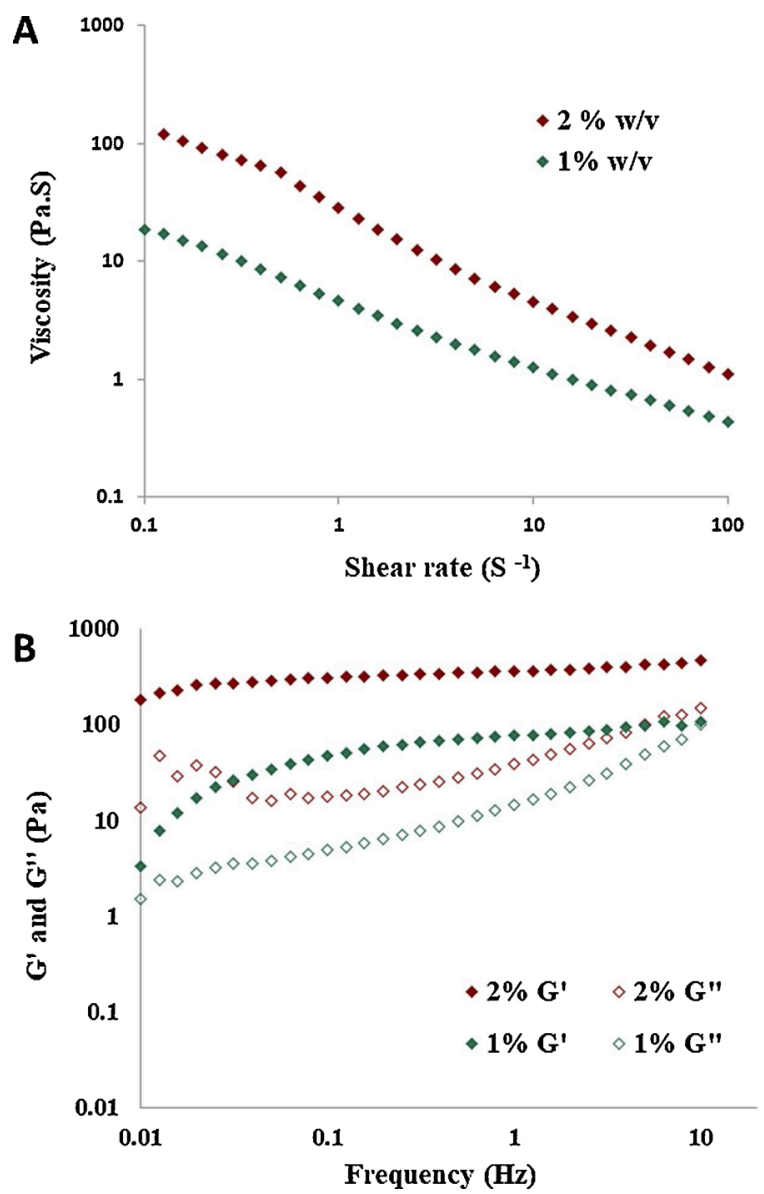

Fig. 7. The rheological profiles of Pickering emulsions stabilized with $1 \% \mathrm{w} / \mathrm{v}$ and $2 \% \mathrm{w} / \mathrm{v}$ chitosan/collagen peptides nanoparticles: (A) Apparent viscosity versus shear rate, and (B) Frequency sweep curves showing values of the storage modulus $\left(G^{\prime}\right)$ and loss modulus $\left(G^{\prime \prime}\right)$.

treated with the Pickering formulation stabilized with $2 \% \mathrm{w} / \mathrm{v} \mathrm{CH} / \mathrm{CP}$ nanoparticles (Fig. 8C and D) compared to the samples treated with the formulation stabilized with $1 \% \mathrm{w} / \mathrm{v}$ nanoparticles (Fig. 8A and B). Moreover, it is noticeable that the highest fluorescence intensity was observed through the entire skin layers (stratum corneum, viable epidermis, and dermis) for the formulation stabilized with $2 \% \mathrm{w} / \mathrm{v} \mathrm{CH} /$ $\mathrm{CP}$ nanoparticles after $24 \mathrm{~h}$ of skin exposure. This observation indicates that a higher degree of penetration was achieved with prolonged skin contact time.
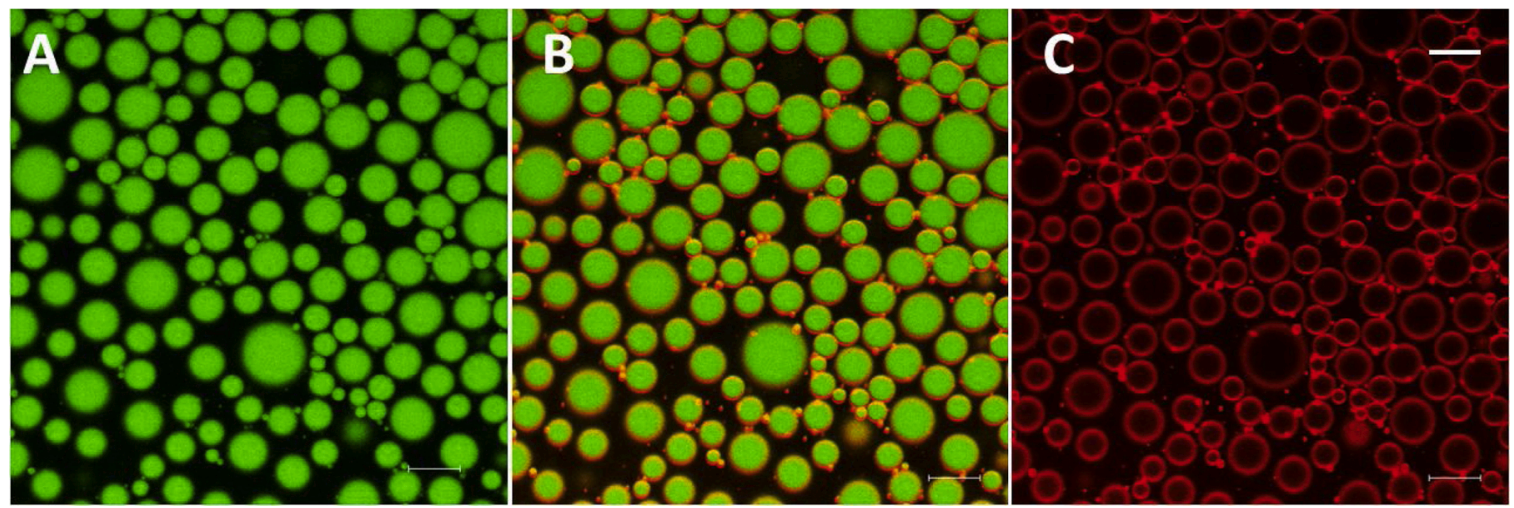

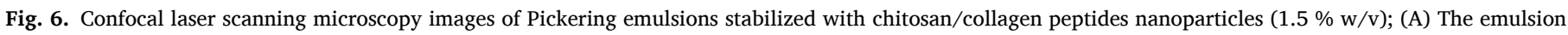

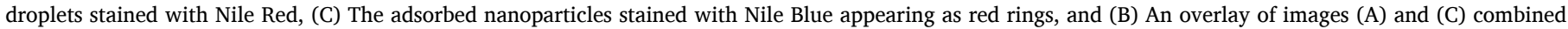
using LAS X software. Scale bar $=10 \mu \mathrm{m}$. 


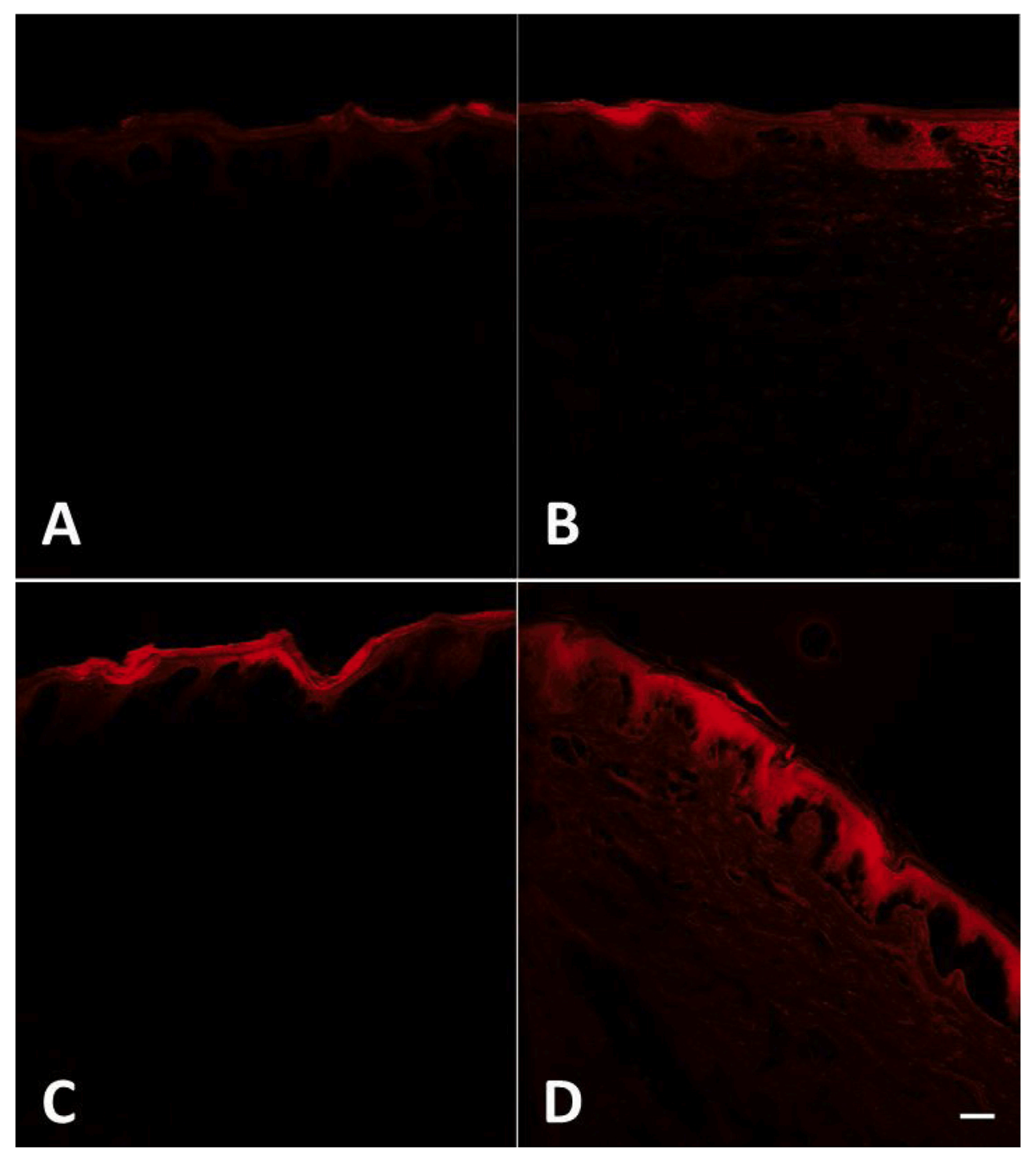

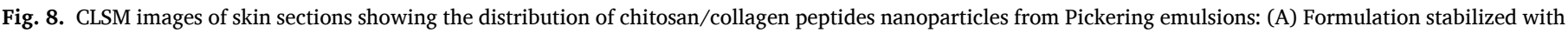

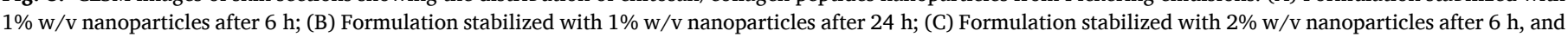
(D) Formulation stabilized with $2 \% \mathrm{w} / \mathrm{v}$ nanoparticles after $24 \mathrm{~h}$. Scale bar $=50 \mu \mathrm{m}$.

It has been reported that polymeric microparticles/microspheres made of natural and synthetic polymers with a diameter ranging between $3 \mu \mathrm{m}$ and $10 \mu \mathrm{m}$ penetrate the skin mainly through hair follicles and to a less extent via diffusion through the stratum corneum. Microparticles with sizes smaller than $3 \mu \mathrm{m}$ penetrate easily by diffusion through the stratum corneum in a high concentration as well as the hair follicles, while those with sizes larger than $10 \mu \mathrm{m}$ remain on the skin surface [64]. However, that study did not discuss the other physicochemical properties of the particles that can influence their penetration at non-follicular regions of the stratum corneum, and it only dealt with aqueous dosage forms as carriers of the particles. In fact, aside from the size, other particle properties such as the surface charge and hydrophobicity have been reported to play an essential role in their penetration through the stratum corneum and deposition in the skin tissue [38]. The size that allows the penetration of the particles through the stratum corneum can be different for particles dispersed in an oil vehicle (such as the case of Pickering emulsions) since the surface of such particles becomes more hydrophobic than the particles dispersed in an aqueous vehicle. This increased hydrophobicity of particles permits them to easily penetrate the stratum corneum through its lipid extracellular pathway [65].

Studies on the skin distribution of the nanoparticles in the viable epidermis and dermis layers resulting from topical Pickering emulsions penetration are very scarce in the available literature. The skin penetration of the Pickering emulsion droplets stabilized with modified cellulose nanocrystals was evaluated in a very recent study [66]. The presence of the nanocrystals in the viable epidermis and dermis was detected $24 \mathrm{~h}$ after skin application. It was concluded that the Pickering emulsion droplets penetrated through the stratum corneum with the nanocrystals adsorbed on their surface due to the small average size of the droplets $(<3 \mu \mathrm{m})$.

The skin penetration of the particles from Pickering emulsions is either achieved through the penetration of the intact emulsion droplets (with the particles being adsorbed on their surface) and/or through the possible breaking up of the emulsion droplets on the skin surface during application, which leads to the releasing of the previously adsorbed particles that eventually penetrate the skin easily [65].

In the present study, the ability of the emulsion droplets stabilized with chitosan/collagen peptides nanoparticles to penetrate the stratum corneum and reach deeper skin layers is attributed mainly to the dominating positive charge of the adsorbed particles (as was discussed in Section 3.1.1). The positively charged chitosan has been reported to open the epidermal tight junctions and disorder the intercellular lipid bilayer as a result of interacting with the negatively charged cells of the 
stratum corneum, which was evident in the slight loosening of the surface layer and the creation of minute microscopic pores (cavitations) in the stratum corneum [67]. Therefore, in the present work, it is suggested that the charge of the cationic chitosan/collagen peptides nanoparticles adsorbed on/stabilizing the Pickering droplets facilitated the passage of the small emulsion droplets through the stratum corneum to deeper layers. Increasing the concentration of the nanoparticles provided a higher positive charge on the surface of the emulsion droplets, and hence led to a deep penetration which was evident in the higher fluorescence intensity in the viable epidermis and dermis (that can be observed in Fig. 8C and D). Furthermore, higher nanoparticle concentration results in a decrease in the droplet size of the produced Pickering emulsion (as discussed previously in Section 3.2.1), and hence allows higher penetration of the emulsion droplets that are smaller in size. Additionally, free particles that can be present in excess in the external phase of Pickering emulsions easily penetrate the stratum corneum due to their small size [65]. The higher concentration of the $\mathrm{CH} / \mathrm{CP}$ nanoparticles $(2 \% \mathrm{w} / \mathrm{v})$ results in the presence of a greater number of available nanoparticles. Some of these nanoparticles could have existed freely in the external phase, and eventually penetrated the stratum corneum and reached the deeper skin layers.

It is noteworthy that the higher viscosity of the Pickering emulsion formulation stabilized with $2 \% \mathrm{w} / \mathrm{v} \mathrm{CH} / \mathrm{CP}$ nanoparticles, comparatively with the formulation stabilized with $1 \% \mathrm{w} / \mathrm{v}$, did not hinder the penetration of the droplets to deep skin layers. It is suggested that the influence of the positive charge and the smaller droplet size predominated over the higher viscosity effects that could have hindered the penetration.

It is also important to mention that no fluorescence was detected in samples withdrawn from the receptor fluid for both formulations $(1 \%$ and $2 \% \mathrm{w} / \mathrm{v}$ ) indicating that no nanoparticles or emulsion droplets permeated the skin, but they were rather retained/localized in the skin. A similar observation was reported by the CLSM tracking of chitosan nanoparticles designed for transdermal delivery [28]. Moreover, it has been reported that nanoparticles designed for topical applications require to be dispersed in a semisolid carrier/vehicle such as hydrogels to ensure the adherence of the nanoparticles to the skin. At the same time, the chosen semisolid vehicle should not interfere with the characteristics of the dispersed nanoparticles system [29]. Therefore, the present study suggests that Pickering emulsions could act as effective platforms for the nanoparticles dermal delivery since the $\mathrm{CH} / \mathrm{CP}$ nanoparticles were able to penetrate the stratum corneum and deposit in the viable epidermis and dermis.

\section{Conclusions}

Chitosan/collagen peptides nanoparticles acted as effective biopolymeric stabilizers for Pickering emulsions. The produced nanoparticles have shown enhanced wettability and a higher ability to reduce the interfacial tension compared to that of chitosan alone, suggesting that the interaction of chitosan with collagen peptides introduced and/ or exposed more hydrophobic moieties. The produced Pickering emulsions demonstrated excellent storage stability, which increased as the nanoparticle concentration increased. No phase separation was observed in the Pickering emulsions stabilized with $\mathrm{CH} / \mathrm{CP}$ nanoparticles at concentrations above $1 \% \mathrm{w} / \mathrm{v}$ during the storage evaluation period of 2 months. The produced Pickering emulsions have shown a shear-thinning behavior and a gel-like structure. Tracking of the $\mathrm{CH} / \mathrm{CP}$ nanoparticles by CLSM after the skin application of the Pickering emulsions confirmed the presence of the nanoparticles in deeper skin layers and not just in the stratum corneum. The degree of skin penetration increased as the concentration of the nanoparticles stabilizing the Pickering emulsions increased. The higher viscosity of the Pickering emulsions, related to the higher nanoparticle concentration, did not influence the degree of skin penetration. Moreover, the degree of skin penetration increased as the contact time of the emulsions with the skin increased. These findings reveal, for the first time, the effective deposition of the chitosan-based nanoparticles in skin layers, which was achieved through the developed Pickering emulsions formulations. These results will be helpful for future studies to expand the application of the produced Pickering emulsions as prospective cosmetic vehicles/ candidates, or as dispersion medium/carriers for the topical delivery of functionalities after evaluating the toxicological profile of the formulations.

\section{CRediT authorship contribution statement}

Asma Sharkawy: Conceptualization, Methodology, Investigation, Writing - original draft. Maria Filomena Barreiro: Supervision, Writing - review \& editing. Alírio E. Rodrigues: Supervision, Writing - review \& editing.

\section{Declaration of Competing Interest}

The authors declare that they have no known competing financial interests or personal relationships that could have appeared to influence the work reported in this paper.

\section{Acknowledgments}

This work was financially supported by the Base Funding-UIDB/ $50020 / 2020$ of the Associate Laboratory LSRE-LCM - funded by national funds through FCT/MCTES (PIDDAC). The work was also supported by the Base Funding-(UIDB/00690/2020) of CIMO-Centro de Investigação de Montanha-funded by national funds through FCT/ MCTES (PIDDAC). The authors gratefully acknowledge the technical support provided by the Instituto de Investigação e Inovação (i3s) at the University of Porto. Asma Sharkawy gratefully thanks the Foundation for Science and Technology (FCT, Portugal) for the doctoral grant (PD/ BD/135085/2017), and Dr. Rui Faria from the LSRE-LCM (University of Porto) for the invaluable discussion.

\section{References}

[1] S. Bom, J. Jorge, H.M. Ribeiro, J. Marto, A step forward on sustainability in the cosmetics industry: a review, J. Clean. Prod. 225 (2019) 270-290, https://doi.org/ 10.1016/j.jclepro.2019.03.255.

[2] D. Venkataramani, A. Tsulaia, S. Amin, Fundamentals and applications of particle stabilized emulsions in cosmetic formulations, Adv. Colloid Interface Sci. 283 (2020), https://doi.org/10.1016/j.cis.2020.102234.

[3] T. Cserháti, E. Forgács, G. Oros, Biological activity and environmental impact of anionic surfactants, Environ. Int. 28 (2002) 337-348, https://doi.org/10.1016/ S0160-4120(02)00032-6.

[4] E. Lémery, S. Briançon, Y. Chevalier, C. Bordes, T. Oddos, A. Gohier, M. A. Bolzinger, Skin toxicity of surfactants: Structure/toxicity relationships, Colloids Surf. A Physicochem. Eng. Asp. 469 (2015) 166-179, https://doi.org/10.1016/j. colsurfa.2015.01.019.

[5] E. Dickinson, Use of nanoparticles and microparticles in the formation and stabilization of food emulsions, Trends Food Sci. Technol. 24 (2012) 4-12, https:// doi.org/10.1016/j.tifs.2011.09.006.

[6] L. Chen, F. Ao, X. Ge, W. Shen, Food-grade pickering emulsions: preparation, stabilization and applications, Molecules 25 (2020), https://doi.org/10.3390/ molecules25143202.

[7] Y. Chevalier, M.A. Bolzinger, Emulsions stabilized with solid nanoparticles: Pickering emulsions, Colloids Surf. A Physicochem. Eng. Asp. 439 (2013) 23-34, https://doi.org/10.1016/j.colsurfa.2013.02.054.

[8] J. Marto, A. Ascenso, S. Simoes, A.J. Almeida, H.M. Ribeiro, Pickering emulsions: challenges and opportunities in topical delivery, Expert Opin. Drug Deliv. 13 (2016) 1093-1107, https://doi.org/10.1080/17425247.2016.1182489.

[9] R.S. Hosseini, A. Rajaei, Potential Pickering emulsion stabilized with chitosanstearic acid nanogels incorporating clove essential oil to produce fish-oil-enriched mayonnaise, Carbohydr. Polym. 241 (2020), https://doi.org/10.1016/j. carbpol.2020.116340.

[10] H. Yang, Z. Su, X. Meng, X. Zhang, J.F. Kennedy, B. Liu, Fabrication and characterization of Pickering emulsion stabilized by soy protein isolate-chitosan nanoparticles, Carbohydr. Polym. 247 (2020), https://doi.org/10.1016/j. carbpol.2020.116712

[11] F. Wu, J. Deng, L. Hu, Z. Zhang, H. Jiang, Y. Li, Z. Yi, T. Ngai, Investigation of the stability in Pickering emulsions preparation with commercial cosmetic ingredients, 
Colloids Surf. A Physicochem. Eng. Asp. 602 (2020), https://doi.org/10.1016/j. colsurfa.2020.125082.

[12] A. Sharkawy, F.M. Casimiro, M.F. Barreiro, A.E. Rodrigues, Enhancing transresveratrol topical delivery and photostability through entrapment in chitosan/ gum arabic Pickering emulsions, Int. J. Biol. Macromol. 147 (2020) 150-159, https://doi.org/10.1016/j.ijbiomac.2020.01.057.

[13] J. Marto, A. Nunes, A.M. Martins, J. Carvalheira, P. Prazeres, L. Gonçalves, A. Marques, A. Lucas, H.M. Ribeiro, Pickering emulsions stabilized by calcium carbonate particles: a new topical formulation, Cosmetics 7 (2020), https://doi. org/10.3390/COSMETICS7030062.

[14] A. Sharkawy, M.F. Barreiro, A.E. Rodrigues, Chitosan-based Pickering emulsions and their applications: a review, Carbohydr. Polym. 250 (2020), https://doi.org/ 10.1016/j.carbpol.2020.116885.

[15] J. Marto, L. Gouveia, I.M. Jorge, A. Duarte, L.M. Gonçalves, S.M.C. Silva, F. Antunes, A.A.C.C. Pais, E. Oliveira, A.J. Almeida, H.M. Ribeiro, Starch-based Pickering emulsions for topical drug delivery: a QbD approach, Colloids Surf. B Biointerfaces 135 (2015) 183-192, https://doi.org/10.1016/j. colsurfb.2015.07.024.

[16] X. Bao, J. Wu, G. Ma, Sprayed Pickering emulsion with high antibacterial activity for wound healing, Prog. Nat. Sci. Mater. Int. (2020), https://doi.org/10.1016/j. pnsc.2020.08.001.

[17] M.H. Asfour, H. Elmotasem, D.M. Mostafa, A.A.A. Salama, Chitosan based Pickering emulsion as a promising approach for topical application of rutin in a solubilized form intended for wound healing: in vitro and in vivo study, Int. J. Pharm. 534 (2017) 325-338, https://doi.org/10.1016/j.ijpharm.2017.10.044.

[18] I. Hamed, F. Ozogul, J.M. Regenstein, Industrial applications of crustacean byproducts (chitin, chitosan, and chitooligosaccharides): a review, Trends Food Sci. Technol. 48 (2016) 40-50, https://doi.org/10.1016/j.tifs.2015.11.007.

[19] B. Bellich, I. D'Agostino, S. Semeraro, A. Gamini, A. Cesàro, "The good, the bad and the ugly" of chitosans, Mar. Drugs 14 (2016), https://doi.org/10.3390/ md14050099.

[20] M. Atarian, A. Rajaei, M. Tabatabaei, A. Mohsenifar, H. Bodaghi, Formulation of Pickering sunflower oil-in-water emulsion stabilized by chitosan-stearic acid nanogel and studying its oxidative stability, Carbohydr. Polym. 210 (2019) 47-55, https://doi.org/10.1016/j.carbpol.2019.01.008.

[21] W.W. Mwangi, K.W. Ho, B.T. Tey, E.S. Chan, Effects of environmental factors on the physical stability of pickering-emulsions stabilized by chitosan particles, Food Hydrocoll. 60 (2016) 543-550, https://doi.org/10.1016/j.foodhyd.2016.04.023.

[22] E.F. Ribeiro, T.T. de Barros-Alexandrino, O.B.G. Assis, A.C. Junior, A. Quiles, I. Hernando, V.R. Nicoletti, Chitosan and crosslinked chitosan nanoparticles: synthesis, characterization and their role as Pickering emulsifiers, Carbohydr. Polym. 250 (2020), https://doi.org/10.1016/j.carbpol.2020.116878.

[23] B.R. Shah, Y. Li, W. Jin, Y. An, L. He, Z. Li, W. Xu, B. Li, Preparation and optimization of Pickering emulsion stabilized by chitosan-tripolyphosphate nanoparticles for curcumin encapsulation, Food Hydrocoll. 52 (2016) 369-377, https://doi.org/10.1016/j.foodhyd.2015.07.015.

[24] P. Cinelli, M.B. Coltelli, F. Signori, P. Morganti, A. Lazzeri, Cosmetic packaging to save the environment: future perspectives, Cosmetics 6 (2019), https://doi.org/ 10.3390/COSMETICS6020026.

[25] A.B.M. Hilmi, A.S. Halim, A. Hassan, C.K. Lim, K. Noorsal, I. Zainol, In vitro characterization of a chitosan skin regenerating template as a scaffold for cells cultivation, Springerplus 2 (2013) 1-9, https://doi.org/10.1186/2193-1801-2-79.

[26] I. Aranaz, N. Acosta, C. Civera, B. Elorza, J. Mingo, C. Castro, M. de los L. Gandía, A.H. Caballero, Cosmetics and cosmeceutical applications of chitin, chitosan and their derivatives, Polymers (Basel) 10 (2018), https://doi.org/10.3390/ polym 10020213.

[27] Y. Chen, M. Wang, L. Fang, Biomaterials as novel penetration enhancers for transdermal and dermal drug delivery systems, Drug Deliv. 20 (2013) 199-209, https://doi.org/10.3109/10717544.2013.801533.

[28] S.M. Abdel-Hafez, R.M. Hathout, O.A. Sammour, Tracking the transdermal penetration pathways of optimized curcumin-loaded chitosan nanoparticles via confocal laser scanning microscopy, Int. J. Biol. Macromol. 108 (2018) 753-764, https://doi.org/10.1016/j.ijbiomac.2017.10.170.

[29] R. Al-Kassas, J. Wen, A.E.M. Cheng, A.M.J. Kim, S.S.M. Liu, J. Yu, Transdermal delivery of propranolol hydrochloride through chitosan nanoparticles dispersed in mucoadhesive gel, Carbohydr. Polym. 153 (2016) 176-186, https://doi.org/ 10.1016/j.carbpol.2016.06.096.

[30] Z. Li, S. Zheng, C. Zhao, M. Liu, Z. Zhang, W. Xu, D. Luo, B.R. Shah, Stability, microstructural and rheological properties of Pickering emulsion stabilized by xanthan gum/lysozyme nanoparticles coupled with xanthan gum, Int. J. Biol. Macromol. 165 (2020) 2387-2394, https://doi.org/10.1016/j. ijbiomac. 2020.10.100.

[31] H. Hong, H. Fan, M. Chalamaiah, J. Wu, Preparation of low-molecular-weight, collagen hydrolysates (peptides): current progress, challenges, and future perspectives, Food Chem. 301 (2019), https://doi.org/10.1016/j. foodchem.2019.125222.

[32] Z. Zhang, H. Zhu, Y. Zheng, L. Zhang, X. Wang, Z. Luo, J. Tang, L. Lin, Z. Du, C. Dong, The effects and mechanism of collagen peptide and elastin peptide on skin aging induced by D-galactose combined with ultraviolet radiation, J. Photochem. Photobiol. B Biol. 210 (2020), https://doi.org/10.1016/j.jphotobiol.2020.111964.

[33] S.H. Park, Y.J. Jo, Static hydrothermal processing and fractionation for production of a collagen peptide with anti-oxidative and anti-aging properties, Process Biochem. 83 (2019) 176-182, https://doi.org/10.1016/j.procbio.2019.05.015.

[34] M. Offengenden, S. Chakrabarti, J. Wu, Chicken collagen hydrolysates differentially mediate anti-inflammatory activity and type I collagen synthesis on human dermal fibroblasts, food sci, Hum. Wellness 7 (2018) 138-147, https://doi. org $/ 10.1016 /$ j.fshw.2018.02.002.

[35] J. Frelichowska, M.A. Bolzinger, J. Pelletier, J.P. Valour, Y. Chevalier, Topical delivery of lipophilic drugs from o/w Pickering emulsions, Int. J. Pharm. 371 (2009) 56-63, https://doi.org/10.1016/j.ijpharm.2008.12.017.

[36] D. Marku, M. Wahlgren, M. Rayner, M. Sjöö, A. Timgren, Characterization of starch Pickering emulsions for potential applications in topical formulations, Int. J. Pharm. 428 (2012) 1-7, https://doi.org/10.1016/j.ijpharm.2012.01.031.

[37] Z. Khabir, A.E. Guller, V.S. Rozova, L. Liang, Y.J. Lai, E.M. Goldys, H. Hu, K. Vickery, A.V. Zvyagin, Tracing upconversion nanoparticle penetration in human skin, Colloids Surf. B Biointerfaces 184 (2019), https://doi.org/10.1016/j colsurfb.2019.110480.

[38] R. Alvarez-Román, A. Naik, Y.N. Kalia, R.H. Guy, H. Fessi, Skin penetration and distribution of polymeric nanoparticles, J. Control. Release 99 (2004) 53-62, https://doi.org/10.1016/j.jconrel.2004.06.015.

[39] P. Opanasopit, T. Ngawhirunpat, T. Rojanarata, N. Wonglertnirant, P. Songprakhon, T. Subongkot, Visualization of ultradeformable liposomes penetration pathways and their skin interaction by confocal laser scanning microscopy, Int. J. Pharm. 441 (2012) 151-161.

[40] S. Anandhakumar, G. Krishnamoorthy, K.M. Ramkumar, A.M. Raichur, Preparation of collagen peptide functionalized chitosan nanoparticles by ionic gelation method: an effective carrier system for encapsulation and release of doxorubicin for cancer drug delivery, Mater. Sci. Eng. C 70 (2017) 378-385, https://doi.org/10.1016/j. msec.2016.09.003.

[41] P. Lv, D. Wang, Y. Chen, S. Zhu, J. Zhang, L. Mao, Y. Gao, F. Yuan, Pickering emulsion gels stabilized by novel complex particles of high-pressure-induced WPI gel and chitosan: fabrication, characterization and encapsulation, Food Hydrocoll. 108 (2020), https://doi.org/10.1016/j.foodhyd.2020.105992.

[42] R. Meng, Z. Wu, Q.T. Xie, B. Zhang, X.L. Li, W.J. Liu, H. Tao, P.J. Li, Zein/ carboxymethyl dextrin nanoparticles stabilized pickering emulsions as delivery vehicles: effect of interfacial composition on lipid oxidation and in vitro digestion, Food Hydrocoll. 108 (2020), https://doi.org/10.1016/j.foodhyd.2020.106020.

[43] P. Lv, D. Wang, L. Dai, X. Wu, Y. Gao, F. Yuan, Pickering emulsion gels stabilized by high hydrostatic pressure-induced whey protein isolate gel particles: characterization and encapsulation of curcumin, Food Res. Int. 132 (2020), https://doi.org/10.1016/j.foodres.2020.109032.

[44] C.K.S. Singh, H.P. Lim, B.T. Tey, E.S. Chan, Spray-dried alginate-coated Pickering emulsion stabilized by chitosan for improved oxidative stability and in vitro release profile, Carbohydr. Polym. 251 (2021), https://doi.org/10.1016/j. carbpol.2020.117110.

[45] OECD, Guidance Document for the Conduct of Skin Absorption Studies, OECD Series on Testing and Assessment, No. 28, OECD Publishing, Paris, 2004, https:// doi.org/10.1787/9789264078796-en guidance-document-for-the-conduct-of-skinabsorption-studies_9789264078796-en, http://www.oecd-ilibrary.org/enviro nment/.

[46] J. Marto, A. Ascenso, L.M. Gonçalves, L.F. Gouveia, P. Manteigas, P. Pinto, E. Oliveira, A.J. Almeida, H.M. Ribeiro, Melatonin-based pickering emulsion for skin's photoprotection, Drug Deliv. 23 (2016) 1594-1607, https://doi.org/ 10.3109/10717544.2015.1128496.

[47] F. Laredj-Bourezg, M.A. Bolzinger, J. Pelletier, Y. Chevalier, Pickering emulsions stabilized by biodegradable block copolymer micelles for controlled topical drug delivery, Int. J. Pharm. 531 (2017) 134-142, https://doi.org/10.1016/j ijpharm.2017.08.065.

[48] J. Wang, H. Zheng, S. Zhang, J. Li, X. Zhu, H. Jin, J. Xu, Improvement of protein emulsion stability through glycosylated black bean protein covalent interaction with (-)-epigallocatechin-3-gallate, RSC Adv. 11 (2021) 2546-2555, https://doi org/10.1039/d0ra08756d.

[49] B.P. Binks, Particles as surfactants - similarities and differences, Curr. Opin. Colloid Interface Sci. 7 (2002) 21-41, https://doi.org/10.1016/S1359-0294(02)00008-0.

[50] E. Dickinson, Biopolymer-based particles as stabilizing agents for emulsions and foams, Food Hydrocoll. 68 (2017) 219-231, https://doi.org/10.1016/j. foodhyd.2016.06.024.

[51] J. Wu, G.H. Ma, Recent studies of pickering emulsions: particles make the difference, Small 12 (2016) 4633-4648, https://doi.org/10.1002/ smll.201600877.

[52] M. Nikbakht Nasrabadi, S.A.H. Goli, A. Sedaghat Doost, B. Roman, K. Dewettinck, C.V. Stevens, P. Van der Meeren, Plant based Pickering stabilization of emulsions using soluble flaxseed protein and mucilage nano-assemblies, Colloids Surf. A Physicochem. Eng. Asp. 563 (2019) 170-182, https://doi.org/10.1016/j. colsurfa.2018.12.004

[53] K.W. Ho, C.W. Ooi, W.W. Mwangi, W.F. Leong, B.T. Tey, E.S. Chan, Comparison of self-aggregated chitosan particles prepared with and without ultrasonication pretreatment as Pickering emulsifier, Food Hydrocoll. 52 (2016) 827-837, https:// doi.org/10.1016/j.foodhyd.2015.08.019.

[54] H. Zhou, C. Dai, Q. Zhang, Y. Li, W. Lv, R. Cheng, Y. Wu, M. Zhao, Interfacial rheology of novel functional silica nanoparticles adsorbed layers at oil-water interface and correlation with Pickering emulsion stability, J. Mol. Liq. 293 (2019), https://doi.org/10.1016/j.molliq.2019.111500.

[55] A.L.R. Costa, A. Gomes, R.L. Cunha, One-step ultrasound producing O/W emulsions stabilized by chitosan particles, Food Res. Int. 107 (2018) 717-725, https://doi.org/10.1016/j.foodres.2018.02.057.

[56] Z. Du, P. Wang, Gelatin hydrolysate hybrid nanoparticles as soft edible pickering stabilizers for oil-in-water emulsions, Molecules 25 (2020), https://doi.org/ 10.3390/molecules25020393.

[57] X. Feng, H. Dai, L. Ma, Y. Fu, Y. Yu, H. Zhou, T. Guo, H. Zhu, H. Wang, Y. Zhang, Properties of Pickering emulsion stabilized by food-grade gelatin nanoparticles: 
influence of the nanoparticles concentration, Colloids Surf. B Biointerfaces 196 (2020), https://doi.org/10.1016/j.colsurfb.2020.111294.

[58] N. Abdul Hadi, A. Marefati, M. Matos, B. Wiege, M. Rayner, Characterization and stability of short-chain fatty acids modified starch Pickering emulsions, Carbohydr Polym. 240 (2020), https://doi.org/10.1016/j.carbpol.2020.116264.

[59] A. Sharkawy, M.F. Barreiro, A.E. Rodrigues, Preparation of chitosan/gum arabic nanoparticles and their use as novel stabilizers in oil/water Pickering emulsions, Carbohydr. Polym. 224 (2019), https://doi.org/10.1016/j.carbpol.2019.115190.

[60] M. Wahlgren, J. Engblom, M. Sjoo, M. Rayner, The use of micro- and nanoparticles in the stabilisation of pickering-type emulsions for topical delivery, Curr. Pharm. Biotechnol. 14 (2014) 1222-1234, https://doi.org/10.2174/ 1389201015666140317122135.

[61] F. Li, X. Li, K. Huang, Y. Luo, X. Mei, Preparation and characterization of pickering emulsion stabilized by hordein-chitosan complex particles, J. Food Eng. 292 (2021), https://doi.org/10.1016/j.jfoodeng.2020.110275.

[62] I. Özcan, E. Azizoğlu, T. Senyiğit, M. Özyazici, Ö. Özer, Enhanced dermal delivery of diflucortolone valerate using lecithin/chitosan nanoparticles: in-vitro and invivo evaluations, Int. J. Nanomed. 8 (2013) 461-475, https://doi.org/10.2147/ IJN.S40519.
[63] A.K. Yegya Raman, C.P. Aichele, Influence of non-ionic surfactant addition on the stability and rheology of particle-stabilized emulsions, Colloids Surf. A Physicochem. Eng. Asp. 585 (2020), https://doi.org/10.1016/j. colsurfa.2019.124084.

[64] H. Schaefer, F. Watts, C. Papantoniou, C. Mahieu, Cosmetic or Pharmaceutical Composition Containing Microspheres of Polymers or of Fatty Substances Filled With at Least One Active Product, US5292512A, 1994.

[65] J. Frelichowska, M.A. Bolzinger, J.P. Valour, H. Mouaziz, J. Pelletier, Y. Chevalier, Pickering w/o emulsions: drug release and topical delivery, Int. J. Pharm. 368 (2009) 7-15, https://doi.org/10.1016/j.ijpharm.2008.09.057.

[66] S. Hiranphinyophat, A. Otaka, Y. Asaumi, S. Fujii, Y. Iwasaki, Particle-stabilized oil-in-water emulsions as a platform for topical lipophilic drug delivery, Colloids Surf. B Biointerfaces (2020) 111423, https://doi.org/10.1016/j. colsurfb.2020.111423.

[67] B. Sapra, S. Jain, A.K. Tiwary, Transdermal delivery of carvedilol containing glycyrrhizin and chitosan as permeation enhancers: biochemical, biophysical, microscopic and pharmacodynamic evaluation, Drug Deliv. 15 (2008) 443-454, https://doi.org/10.1080/10717540802327047. 